\title{
Copyright Protection of Digital Movies Using the Coalition of Technology and Law in China
}

\author{
Xia Liu1 ${ }^{*}$, Yunfei Zha² \\ ${ }^{1}$ Law School, Fujian University of Technology, Fuzhou, China \\ ${ }^{2}$ Innovation and Entrepreneurship Education School, Fujian University of Technology, Fuzhou, China \\ Email:*liuxia82@163.com
}

How to cite this paper: Liu, X., \& Zha, Y. F. (2018). Copyright Protection of Digital Movies Using the Coalition of Technology and Law in China. Chinese Studies, 7, 259-276.

https://doi.org/10.4236/chnstd.2018.74023

Received: August 7, 2018

Accepted: September 10, 2018

Published: September 13, 2018

Copyright (c) 2018 by authors and Scientific Research Publishing Inc. This work is licensed under the Creative Commons Attribution International License (CC BY 4.0).

http://creativecommons.org/licenses/by/4.0/

(c) (i) Open Access

\begin{abstract}
Copyright protection of digital movie is becoming increasingly important with increasing developing of the information technology. In China, unlimited replication and rapid propagation of the network makes it increasingly difficult to monitor the copyright piracy and illegal dissemination. Currently, encryption and tracking technology is predominantly used for copyright protection of digital film. The law is also committed to combating piracy and protecting copyright. But neither technical protection nor legal protection can achieve the protective effect that is necessary. Every year, the industry loses billions of dollars in revenue and faces the potential loss of hundreds of thousands of jobs. And Chinese laws do not define the consumer's responsibilities. So the legal protection is a little weak in reality. This paper argues that there is a need for an alliance of technology and law. Copyright owners actively carry out technical protection to minimize the impact of piracy. Simultaneously, when the technical protection fails or has loopholes, the law shall punish the infringer severely according to the technical data and proof, and deter the offender. This is the better way to protect the copyright of digital film.
\end{abstract}

\section{Keywords}

Piracy, Copyright Protection, Technology, Law, Digital Film

\section{Introduction}

During the late 1990s, another cinematic transition began, from physical film stock to digital cinema technology. Then globally, movies on film are in decline, while digital content proliferates (Filmbug, 2018). "Interim Provisions of Digital Film Management" issued by the State Administration of Press, Publication, Ratio, Film and Television of the People's Republic of China (SAPPRFT) in 2002, 
defines that the digital signal of film is transmitted through satellite, optical fiber, disk, optical disk and other physical media (Interim Provision of Digital Film Management, 2002). It is shown by digital player and screened by projector. In this way, the problem of film production and distribution cost has been reduced. Meanwhile, with the continual evolution of communication and information technologies, people reap the benefits of freely consuming various digital contents at an increasingly faster speed and in larger quantities (Lee, Paek, \& Fenoff, 2018). Digital movie is no exception. The digital movie is a film that's in the film, processing, and release of the film, part or all of the digital processing technology instead of traditional optical chemistry or physical processing technology, using digital media instead of film (Yan, 2005). Digital movie can be copied at almost no cost through network channels, so the pirates can use it to make a profit and final consumers can make non-commercial copying to entertain themselves. Because variety of pirated movie typically does not deteriorate in quality, the pirates may grab the market from legal operators and make an incumbent producer less profitable. Piracy became one of the biggest threats confronting the digital film industry in China today. Digital piracy, by definition, involves the behavior of "reproducing, using, or distributing information products, in digital formats and/or using digital technology, without the authorization of their legal owners" (Belleflamme \& Peitz, 2014). China's major large and medium-sized cities have the serious problem of piracy in digital film. It is tens of billions of copyright market of digital video in city, but copyright owners' income is less than 1 billion. It shows that nine billion RMB must be safeguarded at least (TechWeb, 2009). And the statistics estimated that which were from Motion Picture Association of America (MPAA), based on the piracy of film of MPAA's seven major film producers, the piracy rate of film in China was $93 \%$ in 2005 (Cotler, Keller, \& Lu, 2009). Piracy caused China's loss of \$2.7 billion in potential revenue in 2005. China's official data, based on the entire audio-visual market, indicated that piracy rates are between 70 and 80 percent (Cotler, Keller, \& Lu, 2009). Piracy is so rampant in China that the authors, based on literature review and empirical research, find out that there are a number of key reasons that aid the growth of digital piracy: 1) The Internet can facilitate digital piracy by providing a borderless domain and opportunities for individuals to congregate and share a variety of information and resources (Lee, Paek, \& Fenoff, 2018). 2) Movie ticket prices make downloading the pirated content very economical in comparison (Phau, Teah, \& Liang, 2016). 3) Consumers could avoid being punished because Chinese laws do not define their responsibilities. 4) In addition, attitudes toward piracy have a significant influence upon the intention to download pirated products.

So the copyright owners increasingly need robust protection against piracy. To protect itself against pirates, the film industry has launched the latest anti-piracy war (Yu, 2004). The film industry makes use a lot of strategies and technical means to protect copyright and resist piracy, such as Digital Rights Management (DRM), encryption technology, Watermarking. The government is 
also increasing their efforts to fight piracy and protect copyright, such as the "sword net" action (China Has Launched a New Campaign to Crack down on Internet Piracy, 2014). China has to start to crack down on Internet piracy by National Copyright Administration of China, State Internet Information Office of China, Ministry of Industry and Information Technology of China and Ministry of Public Security of China since 2005, mainly for online literature, music, video, games, software and other key areas. Yan Xiaohong, deputy director of National Copyright Administration of China, said that "sword net" action has achieved certain results (China Has Launched a New Campaign to Crack down on Internet Piracy, 2014). But according to the survey data, the piracy loss rate of domestic films in China has still up to 55\% in recent years (Rampant Rampant Data Shows That Domestic Film Piracy Rates Are as High as 55\%, 2016). These records only further highlight the rampant digital piracy that is occurring across China. Film studios and lawmakers must collaborate aggressively to combat digital piracy.

This article proceeds as follows: Section 2 provides some background and technical review. Section 3 introduces the legal system and advice for improvement. Section 4 introduces the alliance of technology and law to protect copyright of digital film, while Section 5 summarizes the result.

\section{Technical Protection Measures}

The full digitization of films is an inevitable trend. Although digital movies have many advantages over traditional films, controlling of the content of the digital movie is at of risk. Digital films have been subjected to a variety of infringements, such as illegal copying, illegal dissemination, unlicensed usage.

To some extent, those are piracy. These piracies result in great economic loss to the filmmaker, resulting in disincentive to invest vast sums in this industry. And pirated films have fundamentally damaged the production capacity of China's film industry and have a greater negative impact on private enterprises. Sixty-five percent of surveyed film companies said piracy seriously hindered the development of China's film industry (Research on the Economic Impact of Film Piracy in China, 2006). Some small and medium-sized enterprises have withdrawn from the film industry because they are not profitable or even lose money. For the protection of the film industry and the prosperity of culture, copyright protection for digital movie needs much more efforts.

The copyright owners argue that relying solely on the current law of copyright protection is almost an impossible task; therefore, instead of protecting digital movies through the law and litigation alone, many anti-piracy techniques have been developed or are being developed in the first place (Vashistha, Nallusamy, \& Paul, 2010). The technological protection measures play a crucial role in safeguarding the interests of both copyright owners and lawful users of digital movies. 


\subsection{Encryption Technology}

The copyright of the film and TV works is owned by the producer, but the copyrights of the screenplay, music and other works that make up the film and TV work can be independently, are exercised by the individual authors alone (The Standing Committee of the National People's Congress, 2001). The producers can authorize the movie operators to carry out specific issuance and screening. Then the operators of the film not only directly compete with the film industry for market share, but also grab the opportunity and market with digital piracy. This paper first explores what producers in the movie industry have done to fight unlicensed usage by setting up specific protection technology before screening. Such technology falls under the category of Digital Rights Management (DRM). DRM technologies make it very difficult for a large number of ordinary users to pirate copyrighted movies (Rogers, 2011). One of the most critical technology is encryption. The term "encryption technology" means the scrambling and descrambling of information using mathematical formulas or algorithms (The Digital Copyright Act: Special Tenth Anniversary Edition). Copyright owners develop and employ the encryption technology means to prevent piracy for the sole purpose of restricting access to digital movies of illegal uses. This is the first line of protection for movie copyright. The copyright owners have their rights to sell and assign licenses for their works to provide authorization make targeted distribution and dissemination (Adimoolam, John, \& Gunashanthi, 2013), and can isolate from a wide range of unauthorized users through "encryption technology". The licensee can make the effective distribution and viewing of films by obtaining the encryption key from the original copyright owners. But the encryption technology does not completely protect the copyright of digital movie. Because once encryption is removed from digital movie, or the movie was played after encryption is removed, there is no more control on its dissemination (Barni, Bartolini, \& Cappellini, 1998). In reality, the internet is flooded with pirated sources after several days of first broadcast through unauthorized recording and engraving. Even an hour after it was played, the pirated version of the movie was posted online.

\subsection{Digital Watermarking}

The time for encryption protection is very limited. Obviously, once the film is shown, the digital content of movie will be out of control and other measures are needed to protect movies from piracy. In response to the ever-shifting digital piracy, a variety of techniques are developed and deployed security protection for the digital movies over its full Lifecycle, such as the digital watermarking (Kalker, Depovere, Maes, \& Haitsma, 1999). The digital watermarking techniques add another significant layer of protection, acting towards the owners to trace the source of the violation. Digital watermarking is an effective way to protect the copyright of multimedia data even after its transmission (Kalker, Depovere, Maes, \& Haitsma, 1999). 
1) A digital watermark is a message robustly hidden within another digitized signal such as an image, a piece of music, a video, etc. The watermarking can be regarded as a weak signal superimposed in the strong signal of the film itself which had embedded in the digital movie. Therefore, as long as the strength of the weak signal is not higher than the perceptive threshold of the human visual and auditory system, it is difficult to be perceived by the viewer, and it will not affect the quality of the viewing (Gong, Liu, \& Wang, 2016).

2) The digital watermarking aims at providing protection up to the last level of the content handling in the technical system. In order to reach such protection, it proceeds by robust hiding of a message within the media content itself. This complementary information embedding is achieved by applying imperceptible secret modifications to the content (Delannay \& Damien, 2004). Should the received image be in question, the watermark embedded beforehand can be extracted to indicate the copyright owner of such an image. It makes possible to identify the source, author, creator, owner, distributor, or authorized consumer of digital movie, by means of those unperceivable marks. That accurately discovers the source of unauthorized replicates and track the address of the original source (Langelaar, Setyawan, \& Lagendijik, 2000), and retrace them back to the copyright authorized recipient or legitimate content holder (Adimoolam, John, \& Gunashanthi, 2013). The information obtained by tracing is the factual basis for the right holder to negotiate with the pirates and facilitators and exercise the right, and it can be used as a proof of ownership in front of a court, even to make the copyright owners to win the lawsuit for compensation. So it can play a great deterrent to pirates and facilitators in the content distribution. But no matter what technology is not perfect, there is or will be some defects. Such as, the watermark can only trace the source of piracy, but not prevent piracy in advance. Encryption technology can't stop illegal distribution once it's been released or the movie is played. Some unauthorized people or enterprises may exploit the defects to make profits through piracy.

\section{Improving Copyright Protection Law}

Strategies based on technical measures have been effective, but only to a limited extent, it is limited to the developmental level of technology. The copyright owners could not foresee all challenges that copyright protection technology will meet, and the pirates may speed up breaking restriction of protection technology and seek new ways of piracy. Then economic losses and negative effect for film companies are inevitable. As shown in the following data, under the multiple technical protections, piracy has fundamentally hit the production capacity of Chinese film industry, and has a greater negative impact on private enterprises. According to the Motion Picture Association of America (MPAA), piracy in China caused its loss of $\$ 244$ million in 2005 (Losses of Global Film Piracy Continue to Increase, 2015). Piracy has greatly reduced government's tax revenue of film industry. It can also result in creative people less interested in creative 
works. Then the digital movies need other protection measures to stop further losses, such as legal protection. Piracy means different thing at different environment and different time. The law should clearly define the meaning of piracy of digital movie, identify its connotation and extension, and punish serious legal penalties.

\subsection{Current Copyright Protection Law in China}

Copyright rules and procedures vary from one country to another (Copyright, 2017). Generally, every country makes laws to protect the copyright based on the actual development in technology and economic itself, and maybe some international treaties. Such as WIPO Copyright Treaty: Article 14: Provisions on Enforcement of Rights: (2) Contracting Parties shall ensure that enforcement procedures are available under their law so as to permit effective action against any act of infringement of rights covered by this Treaty, including expeditious remedies to prevent infringements and remedies which constitute a deterrent to further infringements (WIPO Copyright Treaty, 1996). But copyright protection laws of digital movie in particular were notably loosening currently in China. The lack of effective protection for the copyright of digital films has forced the government to continue their efforts to better resist piracy and protect copyright.

1) Civil Liability of Pirates in current law. Copyright Law of the People's Republic of China (PRC) stipulates: Anyone who commits any of the following acts of infringement shall bear civil liability for such remedies as ceasing the infringing act, eliminating the effects of the act, making an apology or paying compensation for damages, depending on the circumstances: (6) exploiting by exhibition, film production or any analogous method of film production, or by adaptation, translation, annotation, or by other means, without the permission of the copyright owner, unless otherwise provided in this Law (Copyright Law of PRC, 2001). As shown above, civil liability is the main form of liability for copyright infringement generally, and compensation for loss is the most important way of civil liability.

Article 48 of Copyright Law of PRC: Where a copyright or a copyright-related right is infringed, the infringer shall compensate for the actually injury suffered by the right holder; where the actual injury is difficult to compute, the damages shall be paid on the basis of the unlawful income of the infringer. The amount of damages shall also include the appropriate fees paid by the right holder to stop the infringing act (Copyright Law of PRC, 2001). Where the right holder's actual injury or infringer's unlawful income cannot be determined, the People's Court shall judge the damages not exceeding RMB 500,000 depending on the circumstances of the infringing act (Copyright Law of PRC, 2001). But it is very common to calculate the damages inaccuracy, and there are a lot of pirates in a short period, because of the infinity of network dissemination. Hence, the copyright owners often hardly obtain appropriate compensation based on the current law. 
Article 31 of China's Film Industry Promotion Act: without the permission of the owner, no one can make a sound recording or video recording of the film being projected. If any person does this, the cinema staff has the right to stop it and request the person to delete it. If he refuses to do that, the cinema staff has the right to ask him to leave the cinema (China's Film Industry Promotion Act, 2016). China's Film Industry Promotion Act was put into effect on March 1, 2017. Article 7: intellectual property related to the film should be protected by law. No organization or individual can infringe upon it. The departments of the people's governments at or above the county level, which are responsible for the enforcement of intellectual property rights, should take measures to protect the intellectual property rights related to movies and investigate and punish law-break behaviors of intellectual property rights related to movies. Citizens, legal persons and other organizations engaged in film activities should enhance their awareness of intellectual property rights and enhance their ability to apply, protect and manage intellectual property rights (China's Film Industry Promotion Act, 2016). China has formulated the regulation and development of the film industry in legal form for the first time. This is a great progress in China's legislation of film. But these rules are not only abstract but also too weak, the actual deterrent force is very weak too. It requires more specific and easy-to-operate legal provisions in China.

Article 36 of Regulation on the Implementation of the Copyright Law of PRC: For any of the tortious acts as mentioned in Article 47 of the Copyright Law which at the same time injures the social public good, a fine of up to three times the illegal proceeds shall be imposed upon the infringement act by the administrative authority of copyright. If it is not easy to calculate the illegal proceeds, a fine of up to 100,000 RMB may be imposed upon the infringement act (Regulation on the Implementation of the Copyright Law of PRC, 2002). But there is a well-known case that one skilled technician has earned millions of RMB through piracy online himself, whose website is http://www.dy161.com/ (One skilled technician has earned millions of RMB through piracy online himself, 2016). It can be seen from the comparison of illegal income and legal compensation that the current illegal cost of piracy is very low, in contrast, the profit of piracy is very high. It is difficult to prevent the piracy and protect the copyright by simply compensating for the loss based on the current civil protection law. The actual legal protection effect of digital movie still needs to be further strengthened to stop further piracy. In other words, China should also strengthen the penal protection of copyright, in addition to increasing compensation.

2) Criminal Liability of Pirates in current law. A copyright owner may receive compensation for damages or profits resulting from the infringements, if he files a lawsuit (Copyright, 2017). And if the infringement act constitutes a crime, the infringer shall be prosecuted for his criminal liability. 1) Recently, the first case in China was sentenced in Hubei province for pirating films. Yanghan Wei was sentenced to 10 months in prison and a fine of 5000 RMB on Sept. 6, 2016, 
which became the first conviction in China for pirating a film (Pirate film will be sentenced, 2016). It warns pirates that the piracy may not only mean a loss of money but also a possible loss of freedom.

In fact, Chinese government has made great efforts on legislation of copyright law for protecting copyright of digital content recently (China IPR Protection Situation, 2005). From the revised Copyright Law in 2001 to new Regulation on the Protection of the Right of Communication of Information on Network launched in 2006, the judicial protection system of copyright law has been revised and strengthened (Tong, Yan, \& Hao, 2008). The applications of copyright law have obvious effects that prohibitions against intentional reproduction of copyrighted works, which is often termed "piracy", are quite strong and well-established (Beard, Ford, \& Sorek, 2018). That is to say, punishing piracy, in addition to the loss of money as mentioned above, may result in pirates' cost in lost liberty. These should discourage entry since rigorous enforcement of such provisions increase certain risks of piracy.

3) The Shortage of Current Law In spite of intellectual property laws for regulation and enforcement, and there are varieties of technical protection measures, the prevalence rate for digital piracy remains very high in China (Lee, Paek, \& Fenoff, 2018).

Chinese laws do not define consumers' legal responsibilities in piracy. Most of them choose to pirated movie without any penalty. Meanwhile, there is no actual credit system in China, dishonesty can not be exposed and will not affect their lives.

The price of piracy is too small for individuals, organizations, and participates. And the consequence of piracy is determined mainly according to the amount of illegal income based on tangible standard in the Criminal Law of PRC. But the illegal profits of piracy of digital movie are often hard to calculate exactly online. This little risk prompted many people willing to piracy.

The destructive power of piracy is astonishing. First, piracy may weaken the Chinese film industry's ability to gain market returns, and increase in research costs of copyright protection technology, fundamentally restricts the development of film industry. Second, piracy restricts the original innovation of film industry, in the long run, it will harm the long-term interests of the consumers growing demand for culture. Third, piracy reduces government's fiscal revenue, and increases the cost of the government's anti-piracy, disrupts the normal social economic order (Research on the Impact on Economy of Piracy in China, 2006). So we must improve the copyright protection law to strengthen the protection effect when the technology protection has expired.

\subsection{Improving Copyright Protection Law in China}

At the moment, piracy is still very serious in China. Statistics show that the domestic film industry is expected to lose more than 1 billion RMB each year due to piracy (It can be located of the pirated source for one hour, when the Film Quality Inspection Institute introduced watermark protection technology, 2016). 
But the compensation of the law is very much lower and a grey area. When somebody filed a lawsuit of copyright infringement, according to a single piece of computation, the compensation of pirating a popular film and television is only tens of thousands of RMB. In the name of unfair competition, the amount of compensation is only about 100,000 RMB to 300,000 RMB (It can be located of the pirated source for one hour, when the Film Quality Inspection Institute introduced watermark protection technology, 2016). But the profits of pirates are often millions. Comparing these two data directly, it is not hard to see why piracy is so rampant in China.

China has to think carefully about how to do better in copyright protection and against piracy. China should learn from good experiences from other countries, when necessary to improve the copyright law. Such as, Trademark law of US banned buying and selling fake and inferior commodities on purpose in the United States, people will face fines of up to $\$ 2$ million and 10 years in prison, and repeat crime individuals will face fines of up to $\$ 5$ million and 20 years in prison (Trademark law of the United States of America, 2009). PROTECT IP Act (PIPA) of US prohibited to reprint, upload, download and use non-self-original resources without copyright permission, otherwise it will be subject to heavy fines and years of imprisonment (PROTECT IP Act, 2012). The United States imposes severe penalties on both buyers and sellers of infringement. This is worth studying in China. Because the number of moviegoers reached 1.37 billion in 2016, it is nearly 8.9 percent growth compared with last year. China has become the world's most populous country (The total domestic movie box office over 45 billions 700 million, and the total number of the world's largest screen in 2016, 2017). The high piracy rate plus the huge moviegoers cause the much more loss and damage of piracy in China. Punishing the large number of moviegoers of pirated movie should be able to play a greater role in curbing piracy.

1) Increase Civil Compensation of Pirates. Section 49 of the amendment of Copyright Act in 2001 makes rule that: the right owner's actual loss or the illegal profits of the violator cannot be determined, People's Court of China can sentence the compensation under $¥ 500,000$, according to the plot of infringing act (The section 49 of the amendment of Copyright Act, 2001). The compensation is too light to deter pirates in China's current law. China should increase the compensation that any person who violates section of Copyright Law, or any regulation issued under copyright law, intentional and for purposes of commercial advantage or private financial gain shall be imposed according to the amount of illegal profits or in accordance with the amount of damage causing to the right owner, or shall be fined not more than $¥ 5,000,000$. Even if any person pirates for personal entertainment needs, he should pay $¥ 5000$ to the copyright owner once. This article of law should be defined clearly in the chapter of compensation and remedies in Copyright Law.

2) Strengthen Copyright Protection in Criminal Law. Simple civil compensation can not be much deterrent for those financial people or enterprises. Pirates should be punished severely to stop further piracy by criminal laws, if the evi- 
dence is sufficient. The first case of movie piracy in China in 2016: the website broadcast pirated film and made profit of 110,000 RMB, in exchange for 10 months in prison. The case is the embodiment of the country's judicial and criminal protection of copyright (Pirate film will be sentenced, 2016). But many people think that piracy is just a mistake, not an law-breaking behavior. But piracy is more insidious and easier to spread in digital world, and it can have a great negative impact on the film industry and the national culture, while piracy is hard to prevent in the simple civil compensation in China. So with the purpose of protecting copyrights better, China's criminal law should clearly define criminal charges for piracy and provides severely penalties for crimes against copyright. That is, any person who violates section of copyright protection law, or any regulation issued under copyright law, and constitutes a crime, should be imprisoned for not more than 5 years, beyond the civil compensation. This will make pirates to know that piracy is illegal and they will be fined much more than profits of piracy and the penalty for personal freedom. That would be a better deterrent.

3) Add Legal Provisions to Define and Punish Users of Pirated Products. The users of pirated products should also be punished accordingly. It should distinguish intention from negligence. Unintentional infringement is also illegal, but it may be treated less harshly by courts than intentional infringement (Copyright, 2017). Eventually, the law-breaking behaviour should be curbed through the use or threat of sanctions (Lee, Paek, \& Fenoff, 2018). In order to do what they are intended to do for the laws, there must be some way to enforce them. There are two types of copyright violation: civil and criminal (Rogers, 2011).

The government should strengthen the construction of network security department of Public Security Bureau and improve the ability of network supervision. When the network security department finds that any person watches or disseminates pirated movie the first time, the network security department should send him the warning email and message. It does inform him the time, website, and content, please stop the violation and delete the content immediately. Meanwhile, the network security department must record the user's information online and upload the electronic records to the credit platform for future reference. The credit platform is built and managed by the government to strengthen integrity management in the whole society.

In 2006, the National Copyright Administration requested that the American Film Institute (IFPI), Business Software Alliance (BSA) China Software Alliance, Kingsoft Co., Ltd., Online Anti-piracy Union, People's Education Press, and other rights holder organizations to collect information about network infringement and piracy cases, and utilize their online reporting systems to widely collect clues and evidence from the public. The National Copyright Administration gathered evidence of 302 cases in only one month's time after starting the special campaign. These cases came from 31 provinces across China. These intensive activities enhanced the profile of the Chinese government in intellectual property right protection (Tong, Yan, \& Hao, 2008). The website of "Wine City 
Cinema" (http://vod.luzhou.net/) has illegally uploaded and disseminated 400 films from the end of 2004 to 2006, including "ghost fog", which are copyrighted by the member companies of MPAA, without the permission of the right holders, and made profits by means of online viewing. The cinema has received the following penalties: 1) To stop the infringements; 2) Fine of 10,000 RMB (The National Copyright Administration of China announced the typical cases of online copyright infringement and piracy in 2006, 2007). These measures can record and provide evidences and digital data for legal sanctions when it is necessary. The "Wine City Cinema" has received the following penalties: 1) To stop the infringements; 2) Fine of 10,000 RMB (The National Copyright Administration of China announced the typical cases of online copyright infringement and piracy in 2006, 2007).

If any person uses or disseminates pirated products, the monitoring system should send the user warning email or message. If the user behaves multiple times, the monitoring system should bring this user into the dishonest blacklist. The Information Department of government should build and improve the credit monitoring, warning and disciplinary mechanism, to promote credit information sharing, to announce and warn the dishonest person, so as to improve the integrity level of the whole society. The website is ceditchina.gov.cn which is just a platform to undertake these functions. And Anhui province has operated the exposure platform of dishonest in April, 2018. The information of the person subjected to execution is released by the new media terminal, such as the PC end of the exposure platform, the Client, the micro-blog, WeChat. The public can inquire the dishonest information any time through the platform (Anhui province has operated the exposure platform of dishonest in April, 2018). This can form the dishonest blacklist. And the government should improve the credit platform and form a nationwide exposure platform of dishonest. Then People's Court of China may grant temporary or permanent injunctions on such terms as Loans from bank for real estate or car, civil servants, career promotion, enjoying social welfare, according to the dishonest blacklist. For instance, it was issued and implemented on September 25, 2016 by General Office of the Communist Party of China and General Office of the State Council of China, which was called "Opinions on speeding up the construction of supervision, warning and punishment mechanism of the dishonest person subject to enforcement" General Office of the Communist Party of China and General Office of the State Council of China, 2016).

Any person who uses pirated products habitually or has other serious plots, such as downloading the movie without authorization and disseminating it, People’s Court of China may be fined not more than $¥ 50,000$ or imprisoned for not more than 5 years, or both. Of course, a copyright owner whose copyright is violated should file a lawsuit to stop further infringements (violations) immediately, when you find the piracy (Copyright, 2017). In this way, the judicial authority can intervene in specific cases more quickly and take measures to protect copyright. 
Those should be clearly stipulated in the relevant laws, such as Information Security Law, Regulation on the Protection of the Right to network Dissemination of Information, Administrative protection method of Internet Copyright, Copyright Law, Criminal Law and so on.

In reality, these users of digital movies may not be aware of the legal consequences associated with unlawful use or sharing of copyrighted content online. The government must tell them the legal rules addressing such behavior through legal advocacy and education (Lee, Paek, \& Fenoff, 2018). Then the law enforcement agencies shall strictly enforce the law. After that, severity and certainty of the punishment should have a direct impact on an individual's attitude toward digital piracy (Lee, Paek, \& Fenoff, 2018).

As mentioned above, it is almost an impossible task, relying solely on the current law or technical measures, the copyright protection for digital movie needs much more efforts.

\section{Coalition of Technologies and Laws}

Today, copyright protection is no longer a complicated issue that is only of interest and concern to copyright lawyers, legal scholars, and technology developers. Rather, it is a matter of public significance, relating to politics, economy, culture and so on, affecting all of us in our daily lives (Yu, 2004). Because despite preventive measures to curb piracy, pirating digital movies remain prevalent in China, impacting a variety of stakeholders-industry officials, copyright owners, and policy makers (Lee, Paek, \& Fenoff, 2018). While a wide range of theoretical perspectives and constructs have been used to explain the technical protection of digital movies, or legal protection in digital copyrights, few studies have simultaneously considered the relationship between technology and law, the operability of the coalition, when cope with the digital piracy (Lee, Paek, \& Fenoff, 2018). The spirit of mutual cooperation is still weak in China, and most of them are only self-reliable and do not form a unified anti-piracy coalition. The practice has proved that legal copyright protection is passive and temporary in nature, while technical protection is active but unavoidably flawed. No single method could find and handle all of piracy. Each different method would give different results (Rogers, 2011), the actual effect of copyright protection is to be tested in a very competitive marketplace.

A more active coalition of technology and law is necessary and urgent. The starting point of this section is the coalition of technology and law to achieve good results of one plus one over two in the fight against piracy and the protection of copyright. Optimal copyright policy, then, necessitates the balancing of these two methods, yet ultimately complementary and promoting each other. The difficult of this section is how to make good cooperation, to win the precious time for each other, minimize the loss caused by piracy.

\subsection{Severe Punishment is the Strong Defense}

Technology has always protected digital movie from its generation to the market 
operation actively. Once electronic content-such as a password to access a website's resources-has been released, it is very difficult to prevent it from being shared. This disclosure often represents economic harm to the content's owner and others. Most attempts to prevent unauthorized sharing of digital content have been based on technology, but these approaches are not always applicable (as with passwords). There are varieties of ways to pirate digital movies illegitimately, and it would seem that there are millions of people around China doing it every time and everywhere (Rogers, 2011).

This means that the first defense line of technology has failed. Then the second line of tracking is about to play its due role. Usually, it's digital watermarking. It could accurate positioning to elaborate of the production, transmission, distribution and projection that made traceable to the last authorized recipient (Rogers, 2011). It can provide digital data for the copyright owners to use commercial negotiation to obtain compensation. If the negotiations are unsuccessful or the result is unsatisfactory, the right holders have better file a lawsuit as soon as possible based on the evidences gathered through technology. The court shall make a proper judgment in accordance with law and facts, and administrative department shall take administrative sanctions. Legal punishment should be carried out to prevent harm or the further damage as soon as possible.

The law has a strong deterrent effect, confirms the legitimate rights of the copyright owners and makes them to obtain compensation for the loss. The law is the last defensive line for copyright protection, capturing and punishing the leaking fish of defensive techniques. At the same time, it can gain valuable time to rearrange the defensive techniques for the copyright owner, and does not make the damage of piracy for further expansion. Many customer may complain about copyright owners' using of legal sanctions to prevent or deter piracy of digital movie. But this is indeed a necessary means of stimulating creative activity and flourishing digital movies. Harsh punishment will deter people from piracy, when the pirates lose a lot of money or even personal freedom according to the copyright protection law.

Without drawing too sharp a line between technology and law, it is a dynamic coalition between technology and law to deal with the changing meaning of digital piracy. In other words, the technology could provide some reliable evidences through the watermarking tracking technology, and the law is the final barrier to copyright. Law enforcers apply the law to crack down on piracy and punish the pirates to stop further piracy. Obviously, the laws designed to imposing legal sanctions on pirates do no work alone. In piracy cases, the pirates must be identified, and evidence must be gathered to make a case against them in court. It needs to use different tools and techniques (Rogers, 2011).

\subsection{Upgrading Technology is the Vanguard of Piracy War}

There is no doubt that law plays an important role in protecting copyright. But the legal protection is passive, does not actively intervene. It needs the copyright 
owner to file a lawsuit, otherwise the courts can not initiate the legal procedure. When the copyright owners lack of or miss evidence, or the right holders think that the lawsuit may outweigh the gains, litigation will not happen, and the legal protection is relatively weak. By all accounts, there are millions of pirates online at any given moment, and clearly copyright holders could never sue every one. In this sense, enforcement is often more about managing the amount of digital piracy going on at any time than it is about suing all piracy (Rogers, 2011). And law enforcement does not have the resources to handle thousands of smaller cases for limited gains (Rogers, 2011). So the lawsuit is suitable for the serious case, because it needs a long period and to take a lot of manpower and material resources. One of examples is the case of Authors Guild v. Google. The Authors Guild, a professional organization that advocates for authors' rights, filed a lawsuit against the Internet company Google Inc. over Google's scanning of millions of copyrighted books. The case took ten years (Copyright, 2017). Meanwhile, the deterrent effect is passive too. People do not break the law if they are afraid of law-breaking consequences. In contrast, some people may take law-breaking behaviors when they have fearless or fluke mind to escape of law risk.

The right holder should have active consciousness that the problem of technology should be good at using technology to restrain firstly under the strong support and affirmation of the law. Copyright security relies more on technical protection under the harsh punishment of the law normally. This means the right holders need to develop technologies that will be carried out in order to identify and address the vulnerabilities of current technical measures, then update the protection technology. The right holders and government should further invest in and accelerate the development of technology in copyright protection. On the one hand, it can solve the problem of proof by means of technology, so as to help the right holders to protect rights quickly and conveniently (Guo Qi, 2015). On the other hand, the government should actively explore the establishment of a transparent, neutral, authoritative credit service platform to record, publicize and manage the credit situation of enterprises and individuals, in order to connect with the social life in the future and warn the faithless.

The law is the strongest rear camp, which is passive but reliable, and frightens all persons within the scope of the law. It can also crack down on pirates, when the right holders file a lawsuit, and the evidence is conclusive. The practice had proved that the law, controlled by lawmakers and law executors, could be relied on in a copyright crisis. And the technology is a flexible fighter. Technical measures, controlled by copyright owners, are much more convenient and common than legal sanction. Though it can't beat the piracy every time and everywhere, it has weathered most of the attacks from piracy, and just leaved a small fraction of the piracy behind it, waiting for the law to dispose. This is the meaning of coalition of law and technology. They keep close cooperation, timely attack piracy and safeguard copyright. 


\subsection{Bound and Mutually Reinforcing between Technology and Law}

Interestingly, the practical differences of copyright protection between technology and law are mirrored in their different in detection and implementation. Technical protection focuses on prevention first. Meanwhile, technology itself is neither good nor bad, it simply is. Technology is neutral; it is what we do with technology that determines whether it protects copyright or damages and makes copyright protection more difficult (Rogers, 2011).

When destruction, that is, piracy occurs, technology of copyright owner begins to track the source of piracy, then the copyright owners negotiate with the relevant person and file a lawsuit, based on evidences obtained by technology. With no specific technology support, copyright owners have no way searching, capturing and keeping evidence to negotiate with pirates and get the compensation from judgment (Tong, Yan, \& Hao, 2008).

In contrast, the law focuses on punishing the pirates after the piracy, when right holders file a lawsuit. The law escorts the copyright owners and maintains the protection technology, and denies or bans law-breaking operations of technology, and punishes law-breaking person with legal sanction. And the pre-set laws serve to warn and deter people after the enactment of the copyright protection law. It is clear that the piracy is illegal and will be punished accordingly. So people dare not break the law in general.

First, protection technology has prevented the piracy from technology rookies. Most pirates who do not have sophisticated computer technology should be stopped by protective technologies. Second, the pre-set laws keep law-abiding people away from piracy. The vast majority of people are more law-abiding and don't pirate when the law doesn't allow it. Third, harsh laws punish pirates, forcing those people, who are probably not very law-abiding persons, to experience the serious consequences of piracy. This forces them to stay away from piracy. These can compress the living space of piracy, and make piracy unprofitable. Then people may dare not pirate, or think that it is not worth piracy.

Hence, the strong defense worked closely with the intrepid vanguard to win the copyright war. Even if piracy is not eliminated completely, the number of piracy will also be greatly reduced. The coalition will win and get the Great Wall of the copyright kingdom.

\section{Conclusion}

In a digital world, the content of digital film travels so quickly and access can be easily attained. The copyright protection of digital film has been a crucial issue. All of the above efforts would play significant roles in copyright protection of digital movie and make protecting content more efficient. But Chinese should be aware that you are still at the very beginning stage (Tong, Yan, \& Hao, 2008), sustained effort is still needed. In fact, it has much distance to travel before it reaches our ideal standard of copyright protection. Improving copyright law, 
enforcing the law and real-time update technology is a large and difficult task. It is necessary for the whole society to work together, especially the effort of law makers, law enforcement agents, technical engineers.

The ideal state is that coalition of technology and law reflect our determination to ensure that piracy in the digital environment must be eliminated before it can become too entrenched. Such coalition focuses on enhanced protection, extended control, criminalization of infringements and effective exclusion mechanisms.

In reality, even if there are relatively comprehensive laws and perfect technology, there is still a gap between ideal and reality. The practical application of compliance obligations through effective enforcement has been, and continues to be, the most difficult area with which to contend. It is fair to say that the copyright protection of digital movies has leaved much to be desired. China must continue to work hard to reduce the impact of piracy.

In terms of digital movies, this study uncovers other possible factors that may affect engagement in digital piracy of movies, which could serve as the basis for future research into the phenomenon of digital piracy.

\section{Conflicts of Interest}

The authors declare no conflicts of interest regarding the publication of this paper.

\section{References}

(2001). The Section 49 of the Amendment of Copyright Act.

(2001). The Standing Committee of the National People's Congress, Article 1. Copyright Law of PRC, Intellectual Property, 430-431.

(2002). Regulation on the Implementation of the Copyright Law of PRC (p. 513). Intellectual Property.

(2005). China IPR Protection Situation.

(2006). Research on the Economic Impact of Film Piracy in China. American Economic Research Centre of Institute of World Economics and Politics Chinese Academy of Social Sciences, 3.

(2006). Research on the Impact on Economy of Piracy in China. https://wk.baidu.com/view/7ee83c4ae45c3b3567ec8b8d.html

(2007). The National Copyright Administration of China Announced the Typical Cases of Online Copyright Infringement and Piracy in 2006. http://www.ncac.gov.cn/chinacopyright/contents/518/133594.html

(2009). Trademark Law of the United States of America.

(2012). PROTECT IP Act.

(2014). China Has Launched a New Campaign to Crack Down on Internet Piracy. http://news.cri.cn/gb/42071/2014/06/13/5931s4575926.htm

(2015). Losses of Global Film Piracy Continue to Increase. http://www.maxlaw.cn/1/20150803/825078413646.shtml

(2016). China's Film Industry Promotion Act. 
http://www.npc.gov.cn/npc/xinwen/2016-11/07/content_2001625.htm

(2016). It Can Be Located of the Pirated Source for One Hour, When the Film Quality Inspection Institute Introduced Watermark Protection Technology.

http://finance.sina.com.cn/roll/2016-12-08/doc-ifxypipu738902.shtml

(2016). One Skilled Technician Has Earned Millions of RMB through Piracy Online Himself.

http://3g.163.com/news/article/A4LE6EFF00014AED.html?clickfrom=baidu_adapt

(2016). Pirate Film Will Be Sentenced.

http://tv.cctv.com/2016/12/01/VIDElFyK8uglW7VdoLv6CrpA161201.shtml

(2016). Rampant Data Shows That Domestic Film Piracy Rates Are as High as 55\%. http://news.sohu.com/20160216/n437528847.shtml

(2017). The Total Domestic Movie Box Office over 45 Billions 700 Million, and the Total Number of the World's Largest Screen in 2016.

http://www.tingvoa.com/html/20170131/431144.html

(2018). Anhui Province Has Operated the Exposure Platform of Dishonest in April. http://www.creditchina.gov.cn/xinyongdongtai/difangxinyongdongtai/201804/t201804 17_113382.html

Adimoolam, M., John, A., \& Gunashanthi, M. (2013). Anti-Piracy for Movies Using Forensic Watermarking. International Journal of Computer Applications, 26.

Barni, M., Bartolini, F., \& Cappellini, V. (1998). Copyright Protection of Digital Images Embedded Unperceivable Marks. Preprint submitted to Elsevier Preprint, 2.

Beard, R., Ford, G. S., \& Sorek, G. (2018). Piracy, Imitation, and Optimal Copyright Policy. Southern Economic Journal, 817.

Belleflamme \& Peitz. (2014). 1. Chinese City Film and Television Copyright Investigation Report: Internetcafe Piracy Rate 89.4\%, TechWeb, (2009).

http://www.techweb.com.cn/news/2009-11-18/473027.shtml

Copyright (2017). Funk \& Wagnalls New World Encyclopedia (pp. 2-4).

Cotler, K., \& Lu, T. H. (2009). Marketing in China: How Does Warner Deal with the Piracy Market in China (pp. 95-97). Beijing: China Renmin University Press

Delannay, D. (2004). Digital Watermarking Algorithms Robust against Loss of Synchronization (p. 4).

General Office of the Communist Party of China and General Office of the State Council of China (2016). Opinions on Speeding up the Construction of Supervision, Warning and Punishment Mechanism of the Dishonest Person Subject to Enforcement.

Gong, B., Liu, J., \& Wang, W. (2016). Forensic Watermark Defends the Copyright of Digital Film. Advanced Motion Picture Technology, 5.

Interim Provision of Digital Film Management, Article 2. (2002). The State Administration of Press, Publication, Ratio, Film and Television of the People's Republic of China.

Kalker, T., Depovere, G., Maes, M., \& Haitsma, J. (1999). The Video Watermarking System for Broadcast Monitoring. Proceedings of the SPIE, 3657, 103-112.

https://doi.org/10.1117/12.344661

Langelaar, G. C., Setyawan, I., \& Lagendijik, R. I. (2000). Watermarking Digital Image and Video Data. IEEE Signal Processing Magazine, 17, 20-46. https://doi.org/10.1109/79.879337

Lee, B., Paek, S. Y., \& Fenoff, R. (2018). Factors Associated with Digital Piracy among Early Adolescents. Children and Youth Service Review, 86, 287-295.

https://doi.org/10.1016/j.childyouth.2018.02.002 
Movie History, Filmbug. (2018). https://www.filmbug.com/dictionary/moviehistory.php

Phau, I., Teah, M., \& Liang, J. (2016). Investigating the Factors Influencing Digital Movie Piracy. Perth, Western Australia: Taylor \& Francis.

Qi, G. (2015). Imperative to Improve China's Digital Copyright System. Chinese Journal of Law, 58 .

Rogers, M. K. (2011). Cyberspace Digital Piracy. Chelsea House, 8, 64-65, 70-71, 80.

The Digital Copyright Act: Special Tenth Anniversary Edition, Publisher of Internet Law \& Regulation, 242.

Tong, Z., Yan, F., \& Hao, J. (2008). Digital Copyright Protection in China. Berlin: Springer Science + Business Media.

Vashistha, A., Nallusamy, R., \& Paul, S. (2010). Nomark: A Novel Method for Copyright Protection of Digital Videos Without Embedding Data. 2010 IEEE International Symposium on Multimedia, 167-174.

WIPO Copyright Treaty (Dec. 20, 1996). Adopted in Geneva.

Yan, X. (2005). Film Art Dictionary. Beijing: China Film Press.

Yu, P. K. (2004). The Escalating Copyright Wars, Occasional Papers in Intellectual Property \& Communications Law. 